\title{
Intimate partner violence against women in the Erbil city of the Kurdistan region, Iraq
}

\author{
Hazha H Al-Atrushi ${ }^{1}$, Namir G Al-Tawil ${ }^{2}$, Nazar P Shabila ${ }^{2 *}$ and Tariq S Al-Hadithi ${ }^{2}$
}

\begin{abstract}
Background: Violence against women is a worldwide problem and serious human rights abuse that occurs among all social, cultural, economic and religious groups. There is a paucity of research on intimate partner violence against women in Iraq, particularly in the Kurdistan region. This study assessed the prevalence of emotional, physical and sexual intimate partner violence against women and the impact of physical violence in Erbil, the main city of the Iraqi Kurdistan region.

Methods: A cross-sectional study was carried out on a convenience sample of 800 Kurdish ever married women. Women (aged 16 to 65 years) attending two public hospitals in Erbil city for reproductive health problems were included in the study. The study was conducted between $1^{\text {st }}$ of October 2009 and $30^{\text {th }}$ of March 2011. Each woman was seen only once. Intimate partner violence was assessed by administering a modified version of the World Health Organization's domestic violence questionnaire through direct interview by a female doctor. Prevalence of intimate partner violence was assessed by timing (lifetime or past year), frequency (once, 2-5 times, $>5$ times), and type (emotional, physical, and sexual violence). Descriptive statistical analysis was conducted with calculation of frequencies and percentages of women who reported different types, severities and impact of intimate partner violence.
\end{abstract}

Results: The prevalence of the overall lifetime and the overall past year intimate partner violence against women was $58.6 \%$ and $45.3 \%$, respectively. The proportions of women experienced at least one form of lifetime intimate partner violence were: $52.6 \%$ for emotional abuse; $38.9 \%$ for physical violence; and $21.1 \%$ for sexual violence, while $43.3 \%$, $15.1 \%$, and $12.1 \%$ of women experienced at least one form of past year emotional, physical and sexual violence, respectively. Among those with lifetime physical violence, $11.6 \%$ were subjected to more serious injuries like stab wound, broken teeth or broken bones.

Conclusions: There is a high prevalence of intimate partner violence, in particular emotional abuse behavior, against the women attending hospitals in Erbil. Physical violence is also a significant problem particularly in terms of its consequences.

\section{Background}

Violence against women is a worldwide problem and a serious human rights abuse that occurs among all social, cultural, economic, and religious groups. A wide range of negative health outcomes and even death had been recognized as consequences of violence [1]. The first ever WHO study on domestic violence recognized intimate partner violence (IPV) as the most common form of violence in women's lives, much more than assault or rape by strangers or acquaintances. The study showed

\footnotetext{
*Correspondence: nazarshabila@gmail.com

${ }^{2}$ Department of Community Medicine, College of Medicine, Hawler Medical University, Erbil, Iraq

Full list of author information is available at the end of the article
}

that women were at higher risk of violence at homes than in the streets and this has serious repercussions on women's health [2]. Sexually and physically abused women by intimate partners have a risk of $50 \%$ to $70 \%$ to develop gynecological, central nervous system, and stress related problems [3].

For women and girls of 16-44 years old, violence is one of the major causes of death and disability. In 1994, a study by the World Bank on ten selected risk factors facing girls and women in this age group, found rape and domestic violence more dangerous than cancer, motor vehicle accidents, war and malaria [4]. Because of its grave impact on the health and wellbeing of women and children, strategies to improve maternal and child

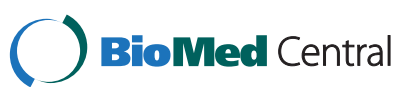


health must include concerted and comprehensive efforts to address violence against women [5].

Intimate partner violence refers to behavior by an intimate partner that causes physical, sexual or psychological harm, including acts of physical aggression, sexual coercion, emotional abuse and controlling behaviors. This definition covers violence by both current and former spouses and other intimate partners [6]. Violence against women is a major public health and human rights concern, with IPV and sexual violence among the most pervasive forms of violence against women. Research has demonstrated a high prevalence of violence against women by intimate partners globally and the associated adverse physical and mental health outcomes, in both the short and long terms $[7,8]$.

The WHO multi-country study on women's health and domestic violence showed that $13 \%$ to $61 \%$ of women between 15 and 49 years old report that an intimate partner has physically abused them at least once in their lifetime and between $6 \%$ and $59 \%$ of women report forced sexual intercourse, or an attempt at it, by an intimate partner in their lifetime [2].

The issue of violence against women in Iraqi Kurdistan region has become a priority in the agenda since 2007 with advocacy of different women's rights and civil society groups. However, there is a paucity of documented knowledge about violence against women in the region. This study is a component of a comprehensive assessment of this important issue of violence against women in Erbil, the main city of the Iraqi Kurdistan region. This component was carried out specifically to explore the prevalence of emotional, physical and sexual IPV against women and the lifetime impact of physical violence in Erbil.

\section{Methods}

\section{Participants/setting}

We invited a sample of 840 women (aged 16 to 65 years) living in Erbil, the main city of the Iraqi Kurdistan region, to participate in this study. The sample included women in contact with the hospitals due to reproductive health problems or their accompanied women. Of the 840 women recruited, 800 (95.2\%) answered the questionnaire and $40(4.8 \%)$ refused to answer. Characteristics of these 800 participants are shown in Table 1.

\section{Measures}

A modified version of the questionnaire designed for the WHO multi-country study on women's health and domestic violence against women [9] was used taking into consideration the modification of other workers [10-12] (Additional file 1). The questionnaire was translated into Kurdish language for interview purpose. The translation was validated by an independent Kurdish
Table 1 Characteristics of women participated in the study

\begin{tabular}{|c|c|c|}
\hline Characteristics & No. & $(\%)$ \\
\hline \multicolumn{3}{|l|}{ Marital status } \\
\hline Married & 753 & $(94.1)$ \\
\hline Widowed & 35 & $(4.4)$ \\
\hline Divorced/Separated & 12 & (1.5) \\
\hline \multicolumn{3}{|l|}{ Age group (years) } \\
\hline $16-25$ & 114 & $(14.2)$ \\
\hline $25-34$ & 276 & $(34.5)$ \\
\hline $35-44$ & 261 & (32.6) \\
\hline $45-54$ & 122 & $(15.3)$ \\
\hline $55-65$ & 27 & (3.4) \\
\hline \multicolumn{3}{|l|}{ Age at marriage (years) } \\
\hline$<18$ & 295 & $(36.9)$ \\
\hline$\geq 18$ & 505 & $(63.1)$ \\
\hline \multicolumn{3}{|l|}{ Duration of marriage (years) } \\
\hline$<5$ & 147 & $(18.4)$ \\
\hline $5.0-15$ & 322 & $(40.2)$ \\
\hline$\geq 16$ & 331 & $(41.4)$ \\
\hline \multicolumn{3}{|l|}{ No. of children } \\
\hline 0 & 101 & $(12.6)$ \\
\hline $1-2$ & 220 & $(27.5)$ \\
\hline$\geq 3$ & 479 & $(59.9)$ \\
\hline \multicolumn{3}{|l|}{ Years of formal education } \\
\hline $0^{*}$ & 303 & (37.9) \\
\hline $1-6$ & 262 & $(32.7)$ \\
\hline $7-9$ & 83 & $(10.4)$ \\
\hline $10-12$ & 47 & $(5.9)$ \\
\hline$>12$ & 105 & $(13.1)$ \\
\hline Total & 800 & $(100.0)$ \\
\hline
\end{tabular}

Illiterate and unschooled.*

native fluent in English language, who translated the Kurdish version back to English to ensure accuracy. In order to protect the confidentiality of the information, names were not included in the written questionnaires.

The content validity of questionnaire was determined by a panel of five experts of different specializations. Experts' comments were taken into consideration in modification and revision. These experts generally agreed that the questionnaire was appropriately designed and developed to measure the phenomenon underlying the study. Questions on being subjected to lifetime physical injuries from physical violence by intimate partner were included.

Prevalence of IPV was assessed by timing (lifetime or past year), frequency (once, 2-5 times, $>5$ times) and type (emotional, physical, and sexual abuse). Emotional abuse was assessed with six items: insult, humiliation, threatening 
to divorce the respondent, threatening to marry another woman, threatening to hurt the respondent and doing things to scare the respondent on purpose. The items in the WHO multi-country study questionnaire for assessing controlling behavior were not included in this study. Physical abuse was assessed with 13 items: slapping, pushing or shaking or throwing things, twisting arm or pulling hair were classified as moderate physical abuse behaviors, whereas hitting, kicking or dragging, choking or burning and threatening with a weapon or using a weapon (gun, knife, or other object) were classified as severe. Sexual abuse was assessed with two items: using physical force to have sexual intercourse when respondent did not want to, and forcing the woman to perform sexual acts that she consider degrading or humiliating.

For each type of abuse, lifetime abuse was defined as the experience of one or more acts at any time from a current or former intimate partner. Abuse taking place within the past year was defined as acts from current partner taking place within the 12 months prior to the interview. Physical injuries were classified as minor (cuts, bruises and aches), serious (sprain, dislocation, eye or ear injuries and burns) and more serious (deep wound, broken bones and broken teeth).

\section{Design and procedure}

This cross-sectional study was conducted in Erbil city between the $1^{\text {st }}$ of October 2009 and the $30^{\text {th }}$ of March 2011. A convenience sample of 800 Kurdish women aged 16-65 years attending two public hospitals in Erbil city for reproductive health problems and their accompanied women were included in the study. Thus, the study does not pretend to be inferred to all women in Kurdistan region.

Women who were too ill to complete the questionnaire or caring for very ill patients, women admitted to the labor room or operating theatre, women who became widow within the last year and women whom husbands were accompanying them were excluded from the study.

Widowed, separated and divorced women were excluded from the estimation of the prevalence of past year violence. The nature of the study was briefly described for each participant. All women were informed that participation in the study was voluntary and the data collected would not be used for anything except for research purpose. Women were interviewed by a female doctor in privacy and were asked not to reveal the topic of the study to their friends and family members including the husband for safety reasons. The data were collected six days per week where four to six women were interviewed each day. The first three days of the week were spent at the Maternity Teaching Hospital and the other three days at the Rizgary Teaching Hospital. Since the data were collected over more than six months and in order to avoid consecutive cases, it was made sure that each woman was interviewed only once.

A pilot study was conducted on 35 women aiming at determining the clarity and the content adequacy of the questionnaire. It also helped in estimating the time required for the data collection and identifying the limitations that might be encountered during data collection. However, this group of women was excluded from the study sample. The questionnaire was simplified and the interview time was reduced from 45-60 minutes to 20-30 minutes.

The study was approved by the Research Ethics Committee of the College of Medicine of Hawler Medical University and institutional approval was obtained from Erbil Directorate of Health, Maternity Teaching Hospital and Rizgary Teaching Hospital to carry out the study. A verbal informed consent was obtained from each participant. The guidelines of the WHO including the importance of ensuring confidentiality and privacy were followed [13].

\section{Statistical analysis}

The Statistical Package for Social Sciences (SPSS) version 18 was used for data entry and analysis. A descriptive approach was used to calculate frequencies and percentages of women who reported different types, severities and impact of IPV.

\section{Results}

\section{Socio-demographics}

The mean age \pm SD of study participants was $35.18 \pm$ 9.69 years (range 17 to 65 years). Details of sociodemographic characteristics of study participants are shown in Table 1.

\section{Overall violence}

Over $58 \%$ of study participants were subjected to any type of lifetime IPV. Emotional abuse was the most common type $(52.6 \%)$ followed by physical and sexual violence (38.9\% and $21.1 \%$, respectively). Out of 753 married women (excluding widowed, separated and divorced), 45.3\% experienced past year violence where 43.3\%, 15.1\%, and $12.1 \%$ of women were subjected to emotional, physical and sexual violence, respectively.

\section{Emotional abuse}

Emotional abuse was the most common type of lifetime IPV (52.6\%). High proportions of women were subjected to insult (40\%) and intimidation or scaring (38.3\%), compared to $12.6 \%, 12 \%$, and $11.5 \%$ of the total sample who were subjected to threat to marry another woman, harm, and divorce by their partners during their life, respectively. One fifth of the study participants were subjected to humiliation. More than half of victims of emotional abuse 
have been exposed to such acts many times (> 5 times) during their lives. Emotional abuse was again the most common type of past year IPV (43.3\%). Slightly less than one third of women were subjected to insult and scare in the past year (32.3\% and 31.6\%, respectively). Details of lifetime and past year emotional abuse by intimate partners are shown in Table 2.

\section{Physical violence}

Physical violence constituted $38.9 \%$ of lifetime IPV. The most frequent act of physical violence was slapping on face $(35.5 \%)$ and a low proportion of the participants reported chocking or burning (3.0\%). Prevalence of the past year physical IPV was $15.1 \%$, where slapping was still regarded as the commonest type and choking or burning was considered the least common. The lifetime prevalence of moderate physical violence was greater than that of severe physical violence ( $21 \%$ vs. $17.9 \%)$. In contrast, the past year prevalence of severe physical violence was higher than moderate physical violence (8.9\%, vs. 6.2\%). Details of lifetime and past year physical IPV against women are shown in Table 3. Two hundred and eighty two women (40.3\%) out of the 699 women who had children were subjected to lifetime physical IPV. Nearly half of physical attacks (49.3\%) had been committed in front of women's children.

\section{Sexual violence}

Prevalence of lifetime sexual IPV against women was $21.1 \%$. Nearly $21 \%$ of the women reported that they had been physically forced to have sexual intercourse during their life by husband and two thirds of them had experienced such act many times ( $>5$ times). In comparison, $10.8 \%$ of the women reported that they were forced to perform sexual acts that they considered degrading or humiliating. Prevalence of past year sexual IPV against women was $12.1 \%$. Eighty eight women (11.7\%) were continuously subjected to having sexual intercourse by physical force in past year and $63.6 \%$ of these victims had experienced such act many times $(>5$ times). Details of prevalence of lifetime and past year sexual IPV against women are shown in Table 4.

\section{Consequences}

Around $43 \%$ of physically abused women by intimate partners had experienced at least one type of physical injuries during their life. Nearly all of the injured women reported minor injuries (cuts, bruises or aches). More than one tenth of physically abused women experienced serious injuries like eye injuries, sprain, dislocation or burns during their life. Over $11 \%$ of physically abused women experienced more serious injuries like stab wounds, broken bones or broken teeth (Table 5).

\section{Discussion}

\section{Overall violence}

This study showed a high prevalence of lifetime IPV (58.6\%) against women. This prevalence is similar to those reported in a hospital-based study in Baghdad (58\%) [14], primary health care centers in Madina, Saudi Arabia (57.8\%) [9], Sivas, Turkey (52\%) [15], Eastern India (56\%) [16] and Jahrom, Iran (64.7\%) [17]. This prevalence is considerably higher than the rates reported

Table 2 Prevalence of lifetime and past year emotional abuse by intimate partner against women

\begin{tabular}{|c|c|c|c|c|c|c|c|c|}
\hline \multirow[t]{3}{*}{ Type of violence } & \multirow{2}{*}{\multicolumn{2}{|c|}{$\begin{array}{c}\text { Prevalence } \\
(\mathrm{n}=\mathbf{8 0 0})\end{array}$}} & \multicolumn{6}{|c|}{ Frequency of violence } \\
\hline & & & \multicolumn{2}{|c|}{ Once } & \multicolumn{2}{|c|}{$2-5$ times } & \multicolumn{2}{|c|}{$>5$ times } \\
\hline & No. & $(\%)$ & No. & $(\%)$ & No. & (\%) & No. & (\%) \\
\hline Lifetime (overall) & 421 & (52.6) & & & & & & \\
\hline Insult & 320 & $(40.0)$ & 8 & $(2.5)$ & 131 & $(40.9)$ & 181 & $(56.6)$ \\
\hline Scaring/intimidation & 306 & (38.3) & 11 & (3.6) & 126 & $(41.2)$ & 169 & $(55.2)$ \\
\hline Humiliation & 165 & (20.6) & 4 & $(2.4)$ & 34 & $(20.6)$ & 127 & $(77.0)$ \\
\hline Threatening to remarry & 101 & (12.6) & 2 & $(2.0)$ & 28 & $(27.7)$ & 71 & $(70.3)$ \\
\hline Threatening to harm & 96 & (12.0) & 4 & $(4.2)$ & 21 & $(21.8)$ & 71 & $(74.0)$ \\
\hline Threatening to divorce & 92 & $(11.5)$ & 6 & $(6.5)$ & 19 & $(20.7)$ & 67 & $(72.8)$ \\
\hline Past year (overall) & 326 & (43.3) & & & & & & \\
\hline Insult & 243 & (32.3) & 7 & $(2.9)$ & 110 & $(45.3)$ & 126 & $(51.8)$ \\
\hline Scaring/intimidation & 238 & (31.6) & 8 & $(3.4)$ & 114 & $(47.9)$ & 116 & $(48.7)$ \\
\hline Humiliation & 130 & $(17.3)$ & 2 & $(1.5)$ & 37 & $(28.5)$ & 91 & $(70.0)$ \\
\hline Threatening to remarry & 66 & $(8.8)$ & 5 & (7.6) & 16 & $(24.2)$ & 45 & $(68.2)$ \\
\hline Threatening to harm & 61 & $(8.1)$ & 5 & $(8.2)$ & 13 & $(21.3)$ & 43 & $(70.5)$ \\
\hline Threatening to divorce & 55 & $(7.3)$ & 4 & $(7.3)$ & 13 & $(23.6)$ & 38 & $(69.1)$ \\
\hline
\end{tabular}


Table 3 Prevalence of lifetime and past year physical violence by intimate partner against women

\begin{tabular}{|c|c|c|c|c|c|c|c|c|}
\hline \multirow[t]{3}{*}{ Type of violence } & \multirow{2}{*}{\multicolumn{2}{|c|}{$\begin{array}{c}\text { Prevalence } \\
(\mathrm{n}=\mathbf{8 0 0})\end{array}$}} & \multicolumn{6}{|c|}{ Frequency of violence } \\
\hline & & & \multicolumn{2}{|c|}{ Once } & \multicolumn{2}{|c|}{$2-5$ times } & \multicolumn{2}{|c|}{$>5$ times } \\
\hline & No. & (\%) & No. & (\%) & No. & $(\%)$ & No. & $(\%)$ \\
\hline Life time (overall) & 311 & $(38.9)$ & & & & & & \\
\hline Moderate physical violence (overall) & 168 & $(21.0)$ & & & & & & \\
\hline Slapping on face ${ }^{*}$ & 284 & $(35.5)$ & 70 & $(24.6)$ & 109 & $(38.4)$ & 105 & $(37.0)$ \\
\hline Pushing/shaking/throwing something* & 137 & $(17.1)$ & 17 & $(12.4)$ & 38 & $(27.7)$ & 82 & $(59.9)$ \\
\hline Twisting arm/pulling hair* & 114 & 14.3) & 8 & $(7.0)$ & 35 & $(30.7)$ & 71 & $(62.3)$ \\
\hline Severe physical violence (overall) & 143 & $(17.9)$ & & & & & & \\
\hline Hitting with fist/somethingt & 135 & $(16.9)$ & 16 & $(11.9)$ & 45 & (33.3) & 74 & $(54.8)$ \\
\hline Kicking/dragging $†$ & 103 & $(12.9)$ & 9 & $(8.7)$ & 31 & $(30.1)$ & 63 & $(61.2)$ \\
\hline Threatening/attacking with knife or gunt & 27 & (3.4) & 2 & $(7.4)$ & 5 & $(18.5)$ & 20 & $(74.1)$ \\
\hline Choking/burning $†$ & 24 & (3.0) & 8 & $(33.3)$ & 1 & $(4.2)$ & 15 & $(62.5)$ \\
\hline Pat year (overall) & 114 & $(15.1)$ & & & & & & \\
\hline Moderate physical violence (overall) & 50 & $(6.2)$ & & & & & & \\
\hline Slapping on face* & 105 & $(13.9)$ & 21 & $(39.9)$ & 49 & $(20.0)$ & 35 & $(33.3)$ \\
\hline Pushing/shaking/throwing something* & 63 & $(8.4)$ & 6 & $(9.5)$ & 25 & $(39.7)$ & 32 & $(50.8)$ \\
\hline Twisting arm/pulling hair* & 62 & $(8.2)$ & 9 & $(14.5)$ & 22 & $(35.5)$ & 31 & $(50.0)$ \\
\hline Severe physical violence (overall) & 71 & $(8.9)$ & & & & & & \\
\hline Hitting with fist/something + & 65 & (8.6) & 13 & $(20.0)$ & 25 & $(38.5)$ & 27 & $(41.5)$ \\
\hline Kicking/dragging $\dagger$ & 52 & $(6.9)$ & 9 & $(17.3)$ & 19 & $(36.5)$ & 24 & $(46.2)$ \\
\hline Threatening/attacking with knife or gunt & 16 & $(2.1)$ & 2 & $(12.5)$ & 1 & $(6.3)$ & 13 & $(81.3)$ \\
\hline Choking/burning $†$ & 11 & $(1.5)$ & 1 & $(9.1)$ & 0 & $(0.0)$ & 10 & $(90.9)$ \\
\hline
\end{tabular}

*Moderate physical act.

†Severe physical act.

among women attending general practice in some other countries and cities such as Japan (14.3\%) [18], Norway (26.8\%) [19], China (43\%) [20], Esfahan, Iran (36.8\%) [21] and Ireland (39\%) [22]. The wide discrepancies in prevalence of violence may reflect different definitions for violence in every society, the method of screening, religious beliefs and cultural issues [23]. The prevalence of IPV in this study reflects wives being ill-treated by husbands, whereas most similar research in the WHO multi-country study and other countries reflect acts of abuse by "intimate partners", which includes the spouse, ex-spouse, current/former boyfriends or current/former dating partner [24].

The prevalence of lifetime emotional, physical and sexual IPV was high in this study $(52.6 \%, 38.9 \%$, and $21.1 \%$ respectively). Another study from Erbil city that assessed domestic violence (by partners and non-partners) reported a lower prevalence of emotional, physical, and sexual violence $(34.0 \%, 21.6 \%$, and $12.1 \%$, respectively) [25]. The Iraqi family health survey (IFHS) which was

Table 4 Prevalence of lifetime and past year sexual violence by intimate partner against women

\begin{tabular}{|c|c|c|c|c|c|c|c|c|}
\hline \multirow[t]{3}{*}{ Type of violence } & \multirow{2}{*}{\multicolumn{2}{|c|}{$\begin{array}{l}\text { Prevalence } \\
(n=800)\end{array}$}} & \multicolumn{6}{|c|}{ Frequency of violence } \\
\hline & & & \multicolumn{2}{|c|}{ Once } & \multicolumn{2}{|c|}{$2-5$ times } & \multicolumn{2}{|c|}{$>5$ times } \\
\hline & No. & $(\%)$ & No. & $\overline{(\%)}$ & No. & $(\%)$ & No. & $(\%)$ \\
\hline Lifetime (overall) & 169 & $(21.1)$ & & & & & & \\
\hline Physically forced to have sexual intercourse & 166 & (20.8) & 9 & $(5.4)$ & 45 & $(27.1)$ & 112 & $(67.5)$ \\
\hline Forced to perform a sexual act considered degrading or humiliating & 86 & $(10.8)$ & 3 & $(3.5)$ & 32 & $(37.2)$ & 51 & $(59.3)$ \\
\hline Past year (overall) & 91 & $(12.1)$ & & & & & & \\
\hline Physically forced to have sexual intercourse & 88 & $(11.7)$ & 4 & $(4.6)$ & 28 & $(31.8)$ & 56 & (63.6) \\
\hline Forced to perform any sexual act considered humiliating & 52 & $(6.9)$ & 3 & $(5.8)$ & 23 & $(44.2)$ & 26 & $(50.0)$ \\
\hline
\end{tabular}


Table 5 Consequences of lifetime physical violence $(\mathrm{n}=311)^{*}$

\begin{tabular}{lcc}
\hline Type of consequences & No. & (\%) \\
\hline Physical injury (overall) & 134 & $(43.1)$ \\
Cuts, bruises or aches & 132 & $(42.4)$ \\
Eye injuries, sprain, dislocation or burns & 34 & $(10.9)$ \\
Stab wounds, broken bones or broken teeth & 36 & $(11.6)$ \\
\hline
\end{tabular}

*Multiple injuries were possible.

conducted between 2006 and 2007 showed a considerably lower prevalence of emotional and physical IPV against women in Kurdistan region (17.6\% and 10.9\%, respectively) [10]. In Baghdad, 57.3\%, 39.8\%, and $14.9 \%$ of women attending Al-Kadhimiya and Al-Kindy teaching hospitals reported emotional, physical, and sexual IPV, respectively [14], while in southern and central parts of Iraq $35.7 \%$ and $22.7 \%$ of women reported emotional and physical violence, respectively [10]. These low rates in the IFHS could be attributed to the study design of the IFHS which was not specific to the problem of violence only, but included different indicators simultaneously. In addition, the IFHS was a household survey where women expectedly cannot speak freely.

To our knowledge, this study is the first survey in Erbil city to assess the past year IPV. Prevalence of past year IPV in this study (45.3\%) is similar to those reported in Baghdad (44\%) [14], and in Omdurman, Sudan (41.6\%) [26]. However, it is lower than that reported in Madina, Saudi Arabia (58.7\%) [12] and higher than that reported in China 26\% [20] and Esfahan, Iran 29.3\% [21].

Despite the increasing efforts of Iraqi Kurdistan Regional Government by building up civil societies and women's organizations and establishing new police directorate to deal with cases of violence against women and repealing some of the previous Iraqi laws, violence against women continues. According to the Directorate to Trace Violence Against Women in 2009, there were 37, 29 and 19 women's murders in Erbil, Sulaymaniya, and Duhok governorates, respectively; while 1357, 815 and 486 women were reported victims of violence in Erbil, Sulaymaniya, and Duhok governorates, respectively [27].

\section{Emotional abuse}

More than half of women in this study experienced at least one form of emotional abuse. The additional items of threatening to divorce and threatening to remarry represent aspects of emotional abuse that are relevant to women in Erbil but are not included in the WHO multi-country study instrument. These items were also included in IFHS [10]. Nevertheless, it is within the range of the WHO multi-country study; between $20 \%$ and $75 \%$ of women had experienced one or more of these acts, mostly within 12 months [2]. This rate is nearly similar to those reported in Jahrom, Iran (53.5\%) [17], Esfahan, Iran (44.8\%) [21], Sivas, Turkey (53.8\%) [15], and in Eastern India (52\%) [16]. However, it is higher than the rate reported in Madina, Saudi Arabia (32.8\%) [12]. Much higher rates of verbal violence were reported in Jordan (73.4\%) [11] and Karachi, Pakistan (97.5\%) [28]. These differences in prevalence of each type of violence are expected given that the estimates tend to increase in response to broader definitions of the type of violence. Another reason is that the cultural background of male dominated societies further raises the prevalence of violence against women.

\section{Physical violence}

The prevalence of lifetime physical IPV in this study $(35.5 \%)$ is within the range of prevalence in some areas investigated in the WHO multi-country study across different cultures and socio-economic settings (30\%-40\%) such as Namibia, Bangladesh, New Zealand, Thailand, Tanzania, Brazil, and Australia [23,29]. It is slightly lower than those reported among women attending general health practice in Ireland 39\% [22], Sanandaj city, Iran $38 \%$ [30] and in Sivas, Turkey 38.3\% [15]. However, it is slightly higher than the rates reported among a sample of reproductive health clinic attendees in Jordan (31.2\%) [11], at a national community based study in Egypt (34\%) [31], among a sample of pregnant women in Jahrom, Iran (34.7\%) [17] and in Esfahan, Iran (31.9\%) [21]. Much higher rates of lifetime physical violence by partners were reported in rural Bangladesh (67\%) [32], in low socioeconomic communities in Karachi, Pakistan (80\%) [28] and Ethiopia (49\%) [29]. However, much lower figures were reported in Eastern India (16\%) [16], Cambodia (18\%) and Vietnam (25\%) [29].

The prevalence of past year physical violence (15.1\%) is similar to those reported among women attending health care facilities in Sanadaj and Babol of Iran (15\%) [30,33], Dar es Salaam, Tanzania (15\%) and Matlab, Bangladesh (16\%) [29]. A national community based study in Egypt revealed a rate of 13\% [29]. A higher proportion was reported in Israel (32\% among Arab population and 52\% in Gaza Strip) [29], Syria (25-26\%) [34,35] and rural Bangladesh (34.6\%) [32].

The rate of past year severe physical abuse was $8.9 \%$. A higher proportion was reported by women attending primary care facilities in Madina, Saudia Arabia, 16.3\% [12], Egypt 26.6\% [36] and in rural Bangladesh 17.3\% [32]. However, this rate is higher than that reported in Japan city $0.7 \%$, Serbia and Montenegro $1.6 \%$, Thailand $5.1 \%$, and Brazil (3.3\% and 7.5\%) [2].

The lifetime prevalence of severe physical violence of $17.9 \%$ in this study is within the range reported for most of the countries in the WHO multi-country study (13-26\%) 
[2]. However, only three countries (Bangladesh, Japan and Serbia and Montenegro) showed similar findings to this study in terms of having a greater proportion of women experienced only moderate violence than had experienced severe violence.

\section{Sexual violence}

The prevalence of lifetime sexual IPV (21.1\%) is higher than in Baghdad 14.6\% [14], but it is within the range of WHO multi-county study, where most areas fall between $10 \%$ and $50 \%$ [2]. Such similarity to the WHO multi-country study sustains the results of this study as it is based on the same questionnaire and definitions of sexual violence.

Prevalence of past year sexual abuse in this study was around $12.1 \%$. Similar findings were reported in China (12\%) [20], Samoa (11.2\%) and Tanzania (12.8\%) [2]. Higher rates were reported in Bangladesh (20.2\% and 17.1\%), Thailand (15.6\%) and Tanzania 18.3\% [2]. Much higher rates were reported in Ethiopia (44.4\%) [2] and Babol of Iran (42.2\%) [33]. These variations in the prevalence of violence between international studies and this study can be explained by differences in the study setting, study design, and characteristics of the population.

\section{Consequences}

Among physically abused women by husbands; $43.1 \%$ had been ever injured; $10.9 \%$ reported eye injuries, sprains, dislocations or burns; and $11.6 \%$ reported more serious injuries as deep wound, broken bones or broken teeth. This finding is comparable with those of population-based studies which revealed that $40-72 \%$ of all women who have been physically abused by a partner are injured at some point in their life [37]. In Baghdad, domestic violence by husbands was associated with minor injuries in $44.7 \%$ of cases and permanent deformity in $10.9 \%$ of cases [14]. A study in the United States of America revealed that 256 intentionally injured women had a total of 434 contusions and abrasions, 89 lacerations and 41 fractures and dislocations [38]. A WHO multi-country study reported that in Thailand over $20 \%$ of ever-injured women reported that they had been injured more than five times and at least $20 \%$ of ever-injured women in Namibia, Peru, Samoa, Thailand, and Tanzania reported injuries to the eyes and ears [23]. The self-completion module of the 2001 British Crime Survey showed that injuries were often sustained as a result of domestic violence, especially among women. During the worst incidents of domestic violence of women, $46 \%$ sustained minor physical injuries, 20\% moderate physical injuries and $6 \%$ severe physical injuries [39]. In Ireland, a study found that $46 \%$ of women attending the general practice who experienced violent behavior had been injured [22].
The proportion of emotional distress and suicidal thought behaviors and attempts among physically abused women this study was $47.6 \%$ and $32.8 \%$, respectively. This rate agrees with the finding of the self-completion module of the 2001 British Crime Survey which reported that $31 \%$ of women who were subjected to domestic violence developed mental or emotional problems [39]. Higher rates of emotional distress and suicide were reported in Baghdad (71.9\%) [14]. In Nicaragua, 70\% of cases of emotional distress were attributed to IPV [40]. Studies in New Zeland and Spain and the WHO multi-country study, however, revealed negative association between partners' violence and mental health [41].

As the children who live in violent homes are at increased risk of child abuse [42], increased attention is now being focused on the children who witness domestic violence. Research estimates that approximately 3.3 to 10 million children witness the abuse of parent or adult caregiver each year [43]. The American Academy of Pediatrics and its members declared that the abuse of women is a pediatric issue. Identifying and intervening on behalf of battered women may be one of the most effective means of preventing child abuse [44]. Nearly half of physical violence acts in this study occurred in front of women's children. These children may perceive such behavior as usual and acceptable, thus ensuring that the violence will continue. A study conducted at the scenes of police calls for domestic assault in Memphis, Tenn in 1995 found a much higher rate (85\%) of children between the ages of 2 and 17 years old directly witnessed a physical assault [45]. A study from Nicaragua also showed a high rate (49\%) of children who have witnessed a physical assault [40]. A review of more than 36 studies indicated that approximately $30-60 \%$ of children whose mothers are being abused are themselves likely to be abused [46]. More research is needed to develop appropriate screening tools and intervention strategies for children who are at risk.

\section{Limitations}

This study has a number of limitations. The findings cannot be inferred to all women in Iraqi Kurdistan region as the study included a hospital-based convenience sample of participants from Erbil city only. The study is subjected to selection bias due to the different inclusion and exclusion criteria. For example the women whom husbands accompanied them were excluded from the study to allow women feel free to talk about such sensitive issue. These women might be significantly different and possibly under more controlling behaviour than those whose husbands did not accompany them. Controlling behaviour and other forms of domestic violence were not included in the study. Recall bias may significantly underestimate the prevalence of violence particularly for lifetime violence. 


\section{Conclusions}

This study showed that more than half of women were victims of emotional, physical, and or sexual violence at least once by their husbands, and $45.3 \%$ gave history of persistent abuse. The most common type of violence was emotional abuse. A considerable proportion of physically abused women reported injuries from such violence. Minor injuries reported in nearly all injured women. Further research to explore the determinants of IPV against women in an in-depth manner is needed.

\section{Additional file}

Additional file 1: Questionnaire used to assess the prevalence of intimate partner violence against women in Erbil, Iraqi Kurdistan region.

\section{Abbreviations}

IPV: Intimate partner violence; IFHS: Iraqi family health survey.

\section{Competing interests}

The authors declare that they have no competing interests.

\section{Authors' contributions}

HHAA and NGAT conceptualized the study. HHAA, NGAT and TSAH designed the study. HHAA and NGAT collected the data. HHAA, NGAT and NPS carried out data analysis and interpretation. HHAA, NGAT and NPS prepared the manuscript. TSAH extensively reviewed and edited the manuscript.

All authors read and approved the final manuscript.

\section{Acknowledgement}

The authors would like to thank the women who participated in the study.

\section{Author details}

${ }^{1}$ Ministry of Health, Erbil, Iraq. ${ }^{2}$ Department of Community Medicine, College of Medicine, Hawler Medical University, Erbil, Iraq.

Received: 27 February 2013 Accepted: 9 October 2013

Published: 10 October 2013

\section{References}

1. Krug EG, Dahlberg LL, Mercy JA, Zwi AB, Lozano R: World report on violence and health. Geneva: WHO; 2002

2. Garcia-moreno C, Jansen HA, Ellsberg M, Heise L, Watts C: Prevalence of intimate partner violence: finding from WHO multi-country study on women's health and domestic violence. Lancet 2006, 368:1260-1269.

3. Campbell J, Jones AS, Dienemann J, Schollenberger J, O'Campo P, Gielen AC, Wynne C: Intimate partner violence and physical health consequences. Arch Intern Med 2002, 162:1157-1163.

4. Violence against women. http://www.unifem.org/gender_issues/ violence_against_women.

5. Ellsberg M: Violence against women and the millennium development goals: facilitating women's access to support. Int J Gynaecol Obstet 2006, 94:325-332

6. WHO: Responding to intimate partner violence and sexual violence against women: WHO clinical and policy guidelines. Geneva: WHO; 2013.

7. Ellsberg M, Jansen HA, Heise L, Watts CH, Garcia-Moreno C, WHO Multicountry Study on Women's Health and Domestic Violence against Women Study Team: Intimate partner violence and women's physical and mental health in the WHO multi-country study on women's health and domestic violence: an observational study. Lancet 2008, 371(9619):1165-1172.

8. Bott S, Guedes A, Goodwin M, Mendoza J: Violence against women in Latin America and Caribbean: a comparative analysis of population-based data from 12 countries. Washington: Pan American Health Organization; 2012.

9. WHO: Multi-country study on women's health and life experiences questionnaire (version 9). Geneva: WHO; 2000
10. $\mathrm{MOH} /$ Iraq, Central Organization for Statistics and Information Technology, $\mathrm{MOH} /$ Kurdistan, Kurdistan Regional Statistics Office, WHO/Iraq: Iraq family health survey report 2006/2007. Iraq: WHO; 2008.

11. Clark CJ, Bloom DE, Hilli A, Silverman JG: Prevalence estimate of intimate partner violence in Jordan. East Mediterr Health J 2009, 15(4):880-889.

12. Tashkandi AA, Rasheed P: Wife abuse: a hidden problem. A study among Saudi women attending PHC centers. East Mediterr Health J 2009, 15(5):1242-1253.

13. WHO: Putting women first guidelines on ethics and safety for violence research. Geneva: WHO; 1999

14. Abdul Jabbar MA: The prevalence of violence among a group of married women attending two teaching hospitals in Baghdad. Iraq: Iraqi Council for Medical Specializations Thesis. Iraqi Council for Medical Specializations; 2006.

15. Kocacik F, Dogan O: Domestic violence against women in Sivas, turkey: survey study. Croat Med J 2006, 47:742-749.

16. Babu BV, Kar SK: Domestic violence against women in eastern India: a population-based study on prevalence and related issues. BMC Public Health 2009, 9:129.

17. Mohammadhosseini E, Sahraean L, Bubrami T: Domestic abuse before, during and after pregnancy in Jahrom, Islamic Republic of Iran. East Mediterr Health J 2010, 16(7):752-758.

18. Yoshihama M, Horocks J, Kamano S: Experiences of intimate partner violence and related injuries among women in Yokohama, Japan. Am J Public Health 2007, 97(2):232-240.

19. Neroien Al, Scheis B: Partner violence and health: results from the first national study on violence against women in Norway. Scand J Public Health 2008, 36(2):161-168.

20. Xu X, Zhu F, O'Campo P, Koinig MA, Mock V, Campbell J: Prevalence of and risk factors for intimate partner violence in China. Am J Public Health 2005, 95(1):78-85.

21. Mousavi SM, Eshagian A: Wife abuse in Esfahan, Islamic republic of Iran, 2002. East Mediterr Health J 2005, 1(5/6):860-869.

22. Bradley F, Smith M, Long J, O'Dowd T: Reported frequency of domestic violence: cross sectional survey of women attending general practice. BMJ 2002, 324:1-6.

23. Garcia-Moreno $C$, Jansen HAFM, Ellsberg M, Heise L, Watts C: WHO multicountry study on women's health and domestic violence against women: initial results on prevalence, health outcomes, and women's responses. Geneva: WHO; 2005.

24. Saltzman LE, Fanslow JL, McMahon PM, Shelley GA: Intimate partner violence surveillance: uniform definitions and recommended data elements. Atlanta, Georgia: National Center for Injury Prevention and Control; 1999.

25. Kareem H: Domestic violence a fieldwork in the city of Erbil. Erbil, Iraq: Ministry of Culture press; 2008.

26. Ahmed AM, Elmardi AE: A study of domestic violence among women attending a medical center in Sudan. East Mediterr Health J 2005, 11(1/6):164-174

27. Directorate to Trace Violence Against Women: Women's Social condition in Kurdistan region: annual rapport. Erbil: Kurdistan Regional Government; 2009.

28. Ali TS, Bustamante-Gavino I: Prevalence of and reasons for domestic violence among women from low socioeconomic communities of Karachi. East Mediterr Health J 2007, 13(6):1417-1426.

29. Ellsberg $M$, Heise L: Researching violence against women: A practical guide for researchers and activities. WHO, PATH: Washington, DC, United States; 2005.

30. Ghazizadeh A: Domestic violence: a cross-sectional study in an Iranian city. East Mediterr Health J 2005, 11(5/6):880-887.

31. El-Zanaty F, Hussein EM, Shawky GA, Way AA, Kishor S: Egypt demographic and health survey 1995. Macro-International: Calverton, Maryland; 1996

32. Bates LM, Schuler SR, Islam F, Islam MK: Socioeconomic factors and processes associated with domestic violence in rural Bangladesh. Int Fam Plan Perspect 2004, 30(4):190-199.

33. Faramarzi M, Esmailzadeh $\mathrm{S}$, Mosavi S: Prevalence and determinants of intimate partner violence in Babol city, Islamic Republic of Iran. East Mediter Health J 2005, 11(5/6):870-879.

34. Maziak W, Asfar T: Physical abuse in low income women in Aleppo, Syria. Health Care Women Int 2003, 24(4):313-326.

35. Zoepf K: UN finds that $25 \%$ of married Syrian women have been beaten. http://www.nytimes.com/2006/04/11/world/middleeast/11syria.html?_r=0.

36. Akmatov MK, Mikolajczyk RT, Labeb S, Dhaher E, Kkann MM: Factors associated with wife beating in Egypt: analysis of two surveys (1995 and 2005). BMC Womens Health 2008, 8:15 
37. Tjaden $\mathrm{P}$, Thoennes $\mathrm{N}$ : Full report of the prevalence, incidence, and consequences of violence against women. Finding from the national violence against women survey. Washigton: Department of Justice, National Institute of Justice and CDC; 2000.

38. Kyriacou DN, Anglin D, Taliaferro E, Stone S, Tabba T, Linden JA, Muelleman R, Barton E, Kraus JF: Risk factors for injury to women from domestic violence against women. N Engl J Med 1999, 341(25):1892-1898.

39. Walby S, Allen J: Domestic violence, sexual assault and stalking: findings from the British crime survey. London: Home Office; 2004.

40. Ellsberg M, Caldera T, Herrera A, Winkvist A, Kullgren G: Domestic violence and emotional distress among Nicaraguan women: results from population-based study. Am Psychol 1999, 54:30-36.

41. Pico-Alfonso MA, Garcia-Linares Ml, Celda-Navarro N, Blasco-Ros C, Echemburua E, Martinez M: The impact of physical, psychological, and sexual intimate partner violence on women's mental health: depressive symptoms, post traumatic stress disorder, state anxiety, and suicide. J Womens Health 2006, 15(5):599-611.

42. Wright RJ, Wright RO, Issac NE: Response to battered mothers in the pediatric emergency department: a call for an interdisciplinary approach to family violence. Pediatrics 1997, 99(2):186-192.

43. Carlson BE: Children exposed to intimate partner violence: research findings and implications for intervention. Trauma Violence Abuse 2000 1(4):321-340.

44. Thacheray JD, Hibbard R, Dowd MD, Committee on Child Abuse and Neglect, Committee on injury, violence, and Poison Prevention: Intimate partner violence: the role of the pediatrician. Pediatrics 2010, 125(5):1094-1100.

45. Brookoff D, O'Brien KK, Cook CS, Thampson TS, Williams C: Characteristics of participants in domestic violence: assessment of the scene of domestic assault. JAMA 1997, 277(17):1369-1373.

46. Edleson JL: The overlap between child maltreatment and woman battering. Violence Against Women 1999, 5(2):134-135.

doi:10.1186/1472-6874-13-37

Cite this article as: Al-Atrushi et al:: Intimate partner violence against women in the Erbil city of the Kurdistan region, Iraq. BMC Women's Health 2013 13:37.

\section{Submit your next manuscript to BioMed Central and take full advantage of:}

- Convenient online submission

- Thorough peer review

- No space constraints or color figure charges

- Immediate publication on acceptance

- Inclusion in PubMed, CAS, Scopus and Google Scholar

- Research which is freely available for redistribution 